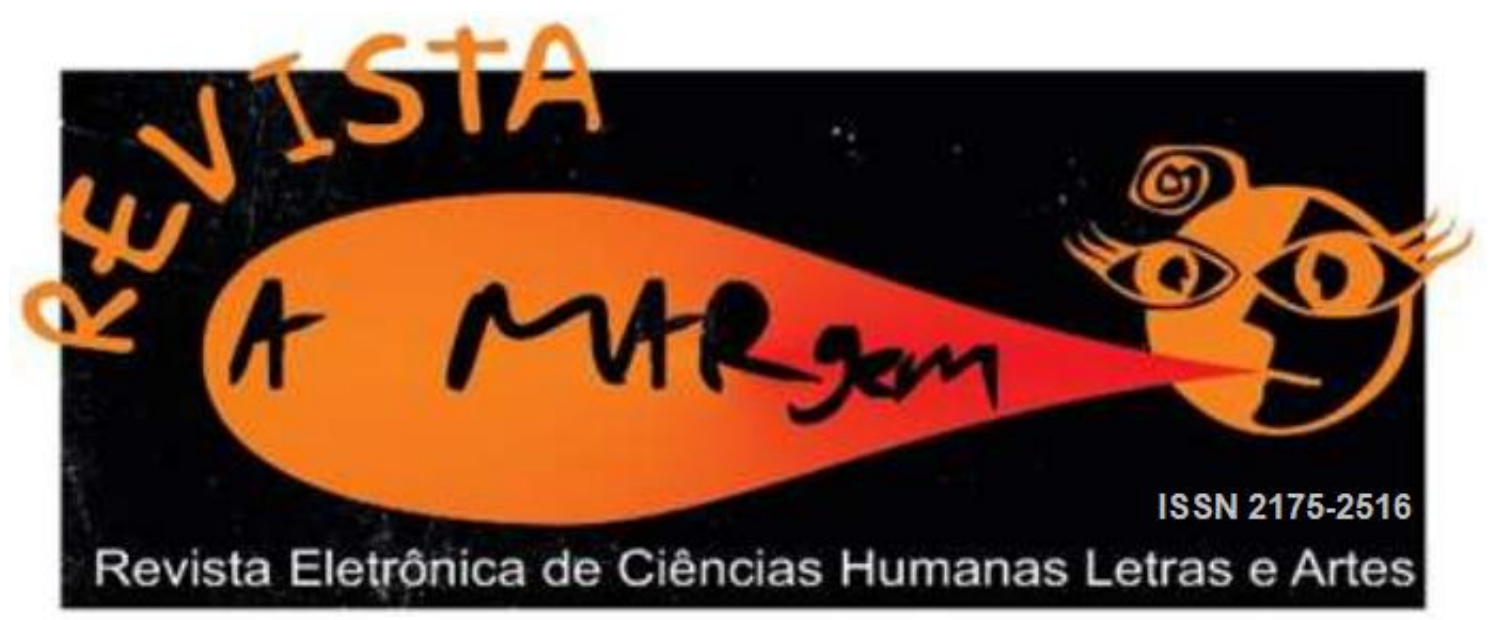

\title{
INVESTIMENTOS E COMUNIDADES IMAGINADAS DE FUTUROS PROFESSORES DE INGLÊS
}

Thais Benitez Kadota

Universidade Estadual de Mato Grosso do Sul (UEMS)

João Fábio Sanches Silva

Universidade Estadual de Mato Grosso do Sul (UEMS)

Resumo: Questões relacionadas à construção identitária vem cada vez mais despertando interesse na comunidade acadêmica como um amplo campo de investigação. Nesta perspectiva, conceitos como investimento, identidades imaginadas e comunidades imaginadas são usados para ajudar a definir esse fenômeno composto por múltiplas camadas, chamado de identidade. A construção da identidade na pós-modernidade ocorre de modo contínuo e de forma aparentemente interminável, uma vez que o indivíduo se relaciona e pertence, ao mesmo tempo a diversos grupos e contextos sociais, que se integram e ajudam a formar a identidade do indivíduo. Embora não definida permanentemente, a identidade assumida por esse individuo afeta diretamente seu modo de ver o mundo e como ele deseja ser visto. A partir dos conceitos acima mencionados, o presente trabalho traz os resultados de um estudo qualitativo que teve por objetivo entender a construção da identidade de um grupo de futuros professores de inglês, enquanto aprendizes e usuários do referido idioma, e o impacto desta construção na sua prática docente ainda em formação. Os dados foram gerados a partir de um questionário aberto com alunos-professores de um curso de Letras Português/Inglês de uma universidade pública da cidade de Campo Grande/MS. Os resultados sugerem que uma vez identificada relações entre comunidades imaginadas e identidades imaginadas no ambiente desses alunos-professores, seus investimentos e o desejo de se apropriar da língua geram impactos nas práticas da língua e na 
formação destes alunos-professores. A compreensão destes conceitos ajudou a entender e construir suas identidades diante desse enredo de conflito e por vezes contraditórias.

Palavras-chave: Identidade. Investimento. Comunidades Imaginadas. Língua Inglesa.

\begin{abstract}
Issues related to identity building have increasingly aroused interest in the academic community as a broad field of research. In this perspective, concepts such as investment, imagined identities and imagined communities are used to help define this multilayered phenomenon, called identity. The construction of identity in postmodernity occurs continuously and in a seemingly interminable way, since the individual relates and belongs at the same time to various social groups and contexts, which integrate and help to form the identity of the individual. Although not permanently defined, the identity assumed by this individual directly affects his or her view of the world and how he/she wishes to be seen. Based on the above mentioned concepts, the present work presents the results of a qualitative study that aimed to understand the construction of the identity of a group of future English teachers, as apprentices and users of that language, and the impact of this construction on their practice teacher still in training. The data were generated from an open questionnaire with students-teachers of a Portuguese / English Literature course at a public university in the city of Campo Grande, MS. The results suggest that once identified relationships between imagined communities and identities imagined in the context of these students-teachers, their investments and the desire to appropriate the language generate impacts on the language practices and the training of these students-teachers. Understanding these concepts helped to understand and build their identities in the context of conflict and sometimes contradictory.
\end{abstract}

Keywords: Identity, investment, imagined communities, English language.

\title{
Introdução
}

A construção identitária vista sob uma abordagem pós-estruturalista pode ser considerada como um campo divergente de opiniões, uma vez que, diante de uma multiplicidade de espaços e contextos sociais, um indivíduo vem a assumir diferentes posições subjetivas, levando em conta diversas relações de poder. Tanto a construção quanto o comportamento, estão inseridos no contexto da "pós-modernidade" que, segundo o sociólogo Bauman (1998, p.20) é a "época ou o estilo de vida em que a colocação em ordem depende do desmantelamento da ordem 'tradicional', herdada e recebida; em que 'ser' significa um novo começo permanente”. Nesse sentido, a construção da identidade e as posições subjetivas dos indivíduos estão em constante transformação e se adequam ao contexto social e às necessidades emergentes. Ainda conforme Bauman:

Certamente, o mundo pós-moderno é qualquer coisa, menos imóvel - tudo, nesse mundo, está em movimento. Mas os movimentos parecem aleatórios, dispersos e destituídos de direção bem delineada (primeiramente, e antes de tudo, uma direção cumulativa). É difícil, talvez impossível, julgar sua natureza "avançada" ou "retrógrada", uma vez que interajustamento entre as dimensões espacial e temporal do passado quase se desintegrou, enquanto os próprios 
espaço e tempo exibem repetidamente a ausência de uma estrutura diferençada ordeira e intrinsecamente.

Dessa forma, enquanto sujeitos detentores de uma identidade e que fazem parte de um contexto social, geogrático, econômico, cultural, etc., essa identidade é delineada continuamente pelos "movimentos aleatórios" citados pelo sociólogo, não sendo possível abordar os conceitos de identidade ou de construção identitária sem considerar as transformações sofridas individualmente pelos seres sociais que, no contexto deste trabalho, são os alunos-professores que estão cotidianamente em contato com as mudanças que se situam na história, no espaço, na ciência e nas circunstancias inerentes às individualidades profissionais, familiares, enfim, aquelas que fazem parte do contexto alheio à formação.

Essas características de inserção do sujeito e da sua identidade despertam interesse na literatura internacional os estudos acerca da construção identitária, tidos como um campo amplo para investigação. Norton (1997) usa o termo identidade para se referir ao modo como as pessoas entendem sua relação com o mundo, como essa relação é construída através do tempo e espaço, e como as pessoas vêem suas possibilidades para o futuro. Para Hall (2006), o sujeito assume identidades diferentes, em diferentes momentos e que não são unificadas, à medida que se vê diante dos mais variados sistemas de significação e representação cultural, onde poderia se identificar com as mais variadas identidades possíveis. Assim como Bhabha (1994), vemos essa identidade como sendo instável e não fixa.

Diante dessa diversidade na construção da identidade, os conceitos sugerem essa formulação identitária como um evento composto por múltiplas camadas e em constante transformação. Mediante a abordagem pós-estruturalista, têm crescido os estudos que tratam das questões de identidade no âmbito da formação de professores de línguas e alguns conceitos relativos à constituição identitária veêm para dar suporte ao entendimento desse processo. Norton (2010) esboçou, dentro de um quadro sociológico, uma conexão significativa entre o desejo do aprendiz de uma língua e o compromisso com a língua alvo, e sua identidade em mudança. A essa conexão ela dá o nome de investimento, no qual argumenta que ao investir na língua-alvo, os aprendizes fazem um investimento na sua própria identidade, acreditando que com isso irão adquirir uma ampla variedade de recursos aumentando o valor de seu capital cultural (Norton 2010). Diferentemente da noção de motivação, a partir da qual considera o aprendiz de uma língua estrangeira como tendo uma personalidade fixa e única, o conceito de 
investimento define esse aprendiz como possuidor de uma identidade complexa que pode sofrer alterações no tempo e espaço e é reproduzida nas interações sociais (Norton 2010).

De grande interesse para as questões de investimento e identidade, surge o conceito de comunidades imaginadas, a que os aprendizes aspiram pertencer ao aprender uma nova língua, assim em Silva (2013, p.4) é possível entender que:

A noção de 'comunidades imaginadas' foi originalmente cunhada por Anderson (1991), que a usou para sugerir que uma nação é socialmente construída e por fim imaginada pelas pessoas que se percebem como parte daquele grupo. Para o autor, "ela é imaginada porque os membros mesmo da menor nação jamais conhecerão a maioria dos seus membros compatriotas, irão encontrá-los, ou se quer ouvir falar deles, mas nas suas mentes repousa a imag€em da sua comunhão" (p.6). Pesquisadores de segunda língua e língua estrangeira adotam o conceito de Anderson que comunidades podem ser imaginadas e o aplicam nas comunidades que os aprendizes de línguas imaginam durante o processo de aprendizagem.

Para Norton (2001), os aprendizes de uma segunda língua têm imagens de comunidades nas quais eles desejam participar no futuro. Ainda segundo a autora, as pessoas nas quais os aprendizes têm os maiores investimentos podem ser as pessoas que representam ou ofereçam acesso à comunidade imaginada. Diante desta perspectiva, Norton (2010) argumenta que ao almejar uma comunidade imaginada é adotada uma identidade imaginada, o investimento de um aprendiz na língua alvo deve ser entendido dentro desse contexto, no qual, segundo a autora (2000, p. 10):

a noção de 'investimento' deve ser entendida dentro de uma ideologia sociológica que faça ligações entre o desejo de um aprendiz e seu comprometimento em aprender uma língua estrangeira, e sua identidade mutável em construção. A noção de 'investimento' considera o aprendiz de línguas como tendo uma história social complexa e múltiplos desejos, e consequentemente, um investimento na língua alvo poderia ser considerado como um investimento na própria identidade do aprendiz.

A partir dos conceitos acima mencionados, observa-se ser de grande importância para o entendimento da construção identitária de futuros professores de inglês compreender a ligação entre investimentos e comunidades imaginadas e sua relação com a língua alvo por alunosprofessores de um curso de graduação em Letras Português/Inglês. Uma vez compreendida que a relação entre investimento e comunidades imaginadas tem seu papel na construção identitária, a verificação de participação e não-participação, bem como o desejo de se apropriar da língua tem seus impactos nas práticas da língua e na formação destes alunos-professores. 
De acordo com Silva (2013, p.3):

Estudos que têm por objetivo investigar a construção identitária tendem a focar particularmente nos aprendizes de inglês como uma segunda língua $\left(\mathrm{ESL}^{1}\right)$, ao contrário de pesquisas que tentam compreender o processo de construção da identidade no contexto de aprendizes de inglês como língua estrangeira $\left(\mathrm{EFL}^{2}\right)$.

É nesse contexto de aprendizes de inglês como língua estrangeira, que este trabalho traz uma abordagem da construção da identidade de professores de inglês em formação, na perspectiva de entender quais os investimentos e quais as comunidades, sejam elas comunidades imaginadas ou de prática, as quais esses sujeitos estiveram, estão ou pretendem estar inseridos futuramente.

\section{Metodologia}

Diante da abordagem pós-estruturalista ao definir a construção identitária como um fenômeno composto por múltiplas camadas, o método de pesquisa qualitativo mostrou-se eficiente em nos ajudar a observar e interpretar a construção identitária, e compreender os significados que os entrevistados atribuem a tal empreendimento. Em relação aos instrumentos qualitativos utilizados, este trabalho adotou um questionário aberto como forma de gerar dados descritivos e oferecer uma análise interpretativa dos dados. Por falta de tempo hábil e disponibilidade dos participantes, uma entrevista semiestruturada não pôde ser realizada, como prevista originalmente no projeto de pesquisa.

A escolha do referido método se justifica segundo Oliveira (2008) para o qual "o pesquisador qualitativo pauta seus estudos na interpretação do mundo real, preocupando-se com o caráter hermenêutico na tarefa de pesquisar sobre a experiência vivida dos seres humanos" (OLIVEIRA, 2008, p.7-8) e, ainda segundo o autor, na pesquisa qualitativa os investigadores imergem no mundo dos sujeitos observados, tentando entender o comportamento real dos informantes, suas próprias situações e como constroem a realidade em que atuam. Dentro desse entendimento, é possível compreender a realidade e as vivências em que os futuros professores de inglês pesquisados estão inseridos ou se situam voluntariamente seja numa perspectiva de

\footnotetext{
${ }^{1}$ ESL: abreviação para English as a second language.

${ }^{2}$ EFL: abreviação para English as a foreign language.
} 
alcançar objetivos inerentes às suas pessoalidades ou de se qualificarem profissionalmente, no contexto desse trabalho, para a docência em língua inglesa.

Os participantes desta pesquisa eram alunos do terceiro ano de um curso de graduação em Letras Português/Inglês de uma universidade pública da cidade de Campo Grande, Mato Grosso do Sul. Acreditamos que este grupo específico dentro do curso de Letras pôde oferecer uma visão ampla sobre suas experiências, dentro e fora do curso de graduação, e se estas experiências afetaram ou não suas vidas e consequentemente sua formação como futuros professores de Inglês.

Desse modo, foi aplicado o questionário aberto com perguntas objetivas, o qual teve por objetivo verificar a relação dos alunos-professores e seu interesse pela língua inglesa, a realização de práticas da língua por parte dos entrevistados, e o entendimento desses alunosprofessores sobre as vantagens e expectativas com relação à língua-alvo. Dentro desse escopo, espera-se verificar como os conceitos anteriormente vistos acerca da construção identitária, tais como investimento e comunidades imaginadas, estão presentes na vida destes alunosprofessores aprendizes e usuários da língua, e se de alguma forma impactam na sua formação como futuros professores de Inglês. Seguem algumas, dentre as perguntas presentes no questionário:

1) O que despertou seu interesse pela língua inglesa? Descreva o que o motivou a aprender o idioma.

2) Como você aprendeu/aprende Inglês? Cite algumas práticas.

3) Como você classificaria seu nível de Inglês? Quais suas expectativas após alcançar um nível mais avançado?

4) Quais são suas expectativas em relação ao idioma após o curso de Letras?

Um total de 12 (doze) pessoas se dispuseram a responder o questionário. Todos eles já tiveram a experiência de investimento em língua inglesa, seja por meio de cursos de idiomas ofertado pela instituição onde estão cursando a graduação em Letras, por meio de escolas de idiomas, por vivência prática do ensino da língua inglesa nos estágios (como o PIBID, por exemplo) ou ainda, atuando como professores de língua inglesa em escolas particulares na educação infantil e/ou em séries iniciais do ensino fundamental.

No tocante ao conceito de investimento, a pergunta: "Como você aprendeu/aprende Inglês? Cite algumas práticas" busca evidenciar práticas na língua alvo e a relação entre os alunos-professores e seus investimentos feitos no idioma. Para compreender o conceito de 
comunidades imaginadas e identidades imaginadas as perguntas: "O que despertou seu interesse pela língua inglesa? e "Quais são suas expectativas em relação ao idioma após o curso de Letras?" por exemplo, buscam compreender como os alunos-professores entrevistados sentemse em relação ao idioma. Mediante os objetivos dessa pesquisa, de compreender a ligação entre investimentos e comunidades imaginadas e sua relação com a construção identitária, essas perguntas constituem alguns parâmetros que podem nos ajudar a discernir sobre essa construção.

Por meio do questionário espera-se compreender como os alunos-professores sentem-se em relação à língua-alvo, verificar suas práticas na língua e ainda, por meio da verificação de expectativas em relação ao idioma, a compreensão da existência de comunidades imaginadas, e se estes componentes influenciam em sua formação docente ainda em construção.

\section{Breve descrição do perfil dos entrevistados}

Conforme já exposto, os entrevistados eram alunos do terceiro ano de um curso de graduação em Letras Português/Inglês de uma universidade pública da cidade de Campo Grande, Mato Grosso do Sul, e do total de 12 entrevistados é possível encontrar o seguinte perfil: 4 participantes estavam de fato inseridos no contexto de investimento em língua inglesa pois, à época, faziam curso de idiomas ou já atuavam como professores durante o estágio do PIBID no ensino médio em uma escola pública (com esse perfil de atuação docente, eram 2 alunos).

Já os demais, ao total 8 alunos, tinham vivenciado o investimento em língua inglesa em cursos de idiomas porém, à época de aplicação dos questionários, só investiam na prática da língua inglesa por meio da graduação, assim sendo, não aplicavam qualquer investimento no ensino-aprendizagem de língua inglesa por meio de estágio, curso de idiomas ou atuação docente além da formação acadêmica.

\section{Considerações sobre o PIBID}

O PIBID (Programa Institucional de Bolsas de Iniciação à Docência), conforme a descrição publicada no site da Coordenação de Aperfeiçoamento de Pessoal de Nível Superior - CAPES (BRASIL, 2018): 
é uma ação da Política Nacional de Formação de Professores do Ministério da Educação (MEC) que visa proporcionar aos discentes na primeira metade do curso de licenciatura uma aproximação prática com o cotidiano das escolas públicas de educação básica e com o contexto em que elas estão inseridas. O programa concede bolsas a alunos de licenciatura participantes de projetos de iniciação à docência desenvolvidos por instituições de educação superior (IES) em parceria com as redes de ensino.

Diante do exposto, ao abordar o perfil dos entrevistados, podemos ver que dois deles estavam inseridos de fato no contexto de investimento em língua inglesa atuando como estagiários, assim sendo, em comparação com os demais, se situavam em um contexto de prática da língua e de ampla moldagem de suas identidades como professores em formação.

E ao estarem inseridos dentro do contexto escolar, lidando com a prática profissional e com as questões que são inerentes ao processo de ensino-aprendizagem, é possível admitir que esses alunos não só investem enquanto aprendizes de um idioma, mas também, investem como professores de língua estrangeira.

Ao abordar esses investimentos, acredita-se não ser viável desvincular a identidade recente de professor - enquanto estagiário - da identidade de aluno, assim é possível dizer que esse sujeito não está somente dentro do conceito de comunidade imaginada como aprendiz de uma língua estrangeira, mas também, como futuro docente - já não mais estagiário - que vislumbra a possibilidade de se inserir posteriormente tanto nas comunidades docentes como nas comunidades de falantes de língua inglesa.

\section{Resultados alcançados/discussões}

O presente trabalho buscou investigar se os investimentos realizados pelos alunosprofessores levaram a alguma comunidade imaginada que pudesse influenciá-los na sua relação como aprendizes e usuários da língua-alvo e, posteriormente na formação como professores de inglês. Os resultados apontam que embora todos os alunos entrevistados de alguma forma invistam na prática da língua, dentro e fora do curso de graduação, suas relações com comunidades imaginadas tomam diferentes rumos, mediante suas expectativas e ideias.

Para alguns alunos-professores investigados, suas comunidades imaginadas baseiam-se em usuários do idioma num nível que eles consideram suficiente para a graduação em Letras. O desejo de se apropriar da língua baseia-se na compreensão por parte de seus futuros alunos, 
quando assim se tornarem professores, e na capacidade didática que os mesmos esperam ter ao lecionar o idioma, se assim desejarem. Visto sob uma perspectiva de integração social e cultural, outros alunos-professores tem em sua comunidade imaginada a identidade imaginada de futuros seres globalizados, imersos em um mundo que exige comunicação entre povos de diferentes nações, e desejam ser capazes de conhecer novas culturas sem a limitação que a falta de domínio da língua inglesa pode trazer.

Embora os alunos-professores invistam na língua-alvo, independente de suas condições ou limitações, sejam elas financeiras ou disponibilidades de tempo e recursos de materiais didáticos, as razões pelas quais os alunos-professores investem tornam-se semelhantes no propósito de se apropriar da língua, porém distinguem-se quanto à identidade imaginada adotada por esses alunos-professores, sejam essas identidades de futuros professores de Inglês ou como usuários do idioma fora de sala de aula.

Ao passo que eles tornam-se conscientes de que sua formação exige um nível de conhecimento e propriedade da língua, muitos enxergam o investimento no idioma como o aperfeiçoamento de uma habilidade primordial para suas carreiras como futuros professores de Inglês. Outros enxergam o investimento na língua como uma aplicação em um requisito recorrente em um mundo onde a língua inglesa tornou-se uma das mais faladas, e a apropriação de tal língua abre as portas para um universo além das salas de aulas.

Devido às relações de poder a que as respostas apontaram, por exemplo, no prestígio entre falantes e não falantes de Inglês e sua utilização na comunicação mundial pôde-se compreender que os alunos-professores aspiram a uma comunidade imaginada, sejam comunidades imaginadas de futuros professores de Inglês ou comunidades imaginadas de viajantes e usuários do idioma. Para alguns essa relação entre investimento e comunidades imaginadas tem seu impacto visto na forma como o aprendiz se posiciona mediante suas aspirações ao dominar a língua. Entretanto, ao mesmo tempo em que aspiram ao domínio da língua-alvo, o impacto desses conceitos na construção de suas identidades como futuros professores de inglês não pode ser identificado.

Os resultados apontam um grande desejo por parte da maioria dos entrevistados em se apropriar da língua. Suas comunidades imaginadas são alimentadas por relações de poder e de prestígio entre os falantes da língua. Os alunos-professores veem como importantes seus investimentos na língua-alvo, nos seus mais variados níveis de apropriação da língua, seja como fluente ou ainda, como suficientes para a graduação num curso de língua estrangeira. 


\section{Conclusões e perspectivas}

À medida que se identificou os investimentos dos alunos - professores e suas devidas comunidades imaginadas, considera-se intrigante o motivo pelo qual alguns alunos resistem em tornarem-se professores de inglês. Enquanto seus desejos de dominar e se apropriar da língua ficam nitidamente claros, a preferência por lecionar a Língua Portuguesa ou ainda, Literatura, predominam como opções de alguns alunos investigados. Essa questão nos estimula a dar continuidade ao processo de pesquisa em busca de respostas que satisfaçam as hipóteses levantadas.

Sugere-se um acompanhamento dos futuros alunos-professores durante o curso de graduação em Letras Português/Inglês na mesma universidade pesquisada, para que seja possível identificar possíveis fatores que tenham ocasionado esses atos de resistência por parte de alguns alunos. Acreditamos que isso possa colaborar para construir identidades de futuros professores de outras habilitações e, juntamente, a capacitação de um futuro professor de inglês. Dessa forma seria possível rever quaisquer fatores que atrapalhem essa identificação com a identidade de um professor de inglês ao longo do curso.

Os resultados sugerem que os investimentos realizados nas práticas da língua reforçam uma identidade assumida por esses alunos-professores, e a presença de comunidades imaginadas, ainda que em conflito com o desejado e o real, permite perceber que suas identidades devem ser entendidas dentro desse contexto. Por fim, pode-se inferir que a construção da identidade é discursivamente construída dentro desses contextos sociais diversificados.

A intenção deste trabalho foi de interpretar como se dá a construção da identidade em futuros professores de inglês, ou alunos-professores. Dessa forma, não houve nenhuma tentativa de estabelecer ou analisar determinado perfil da identidade dos indivíduos, pois como já dito, essa identidade está em constante transformação e, assim, é possível assumir que enquanto sujeitos inseridos no ambiente da educação, suas identidades estão e estarão submetidas ao contexto escolar atual e futuro, lidando com os anseios dos aprendizes que serão conduzidos por eles, com as dificuldades institucionais, pedagógicas e todas as outras que perpassam o fazer docente. 


\section{Referências}

BAUMAN, Z. O mal-estar da Pós-Modernidade. Rio de Janeiro: Jorge Zahar Editor, 1998.

BHABHA, H. The location of culture. London: Routledge, 1994.

HALL, S. A identidade cultural na pós-modernidade. Rio de Janeiro: DP\&A, 2006.

NORTON, B. Non-participation, imagined communities, and the language classroom. In Breen, M. (Org.). Learner contributions to language learning: New directions in research. Harlow: Pearson Education, p.156- 171, 2001.

NORTON, B. Language and Identity. In Hornberger, N. \&McKay, S. (Orgs.) Sociolinguistics and Language Education. Clevedon, UK: MultilingualMatters, p. 349-369, 2010.

NORTON, B. Language and Identity. In Hornberger, N. \&McKay, S. (Orgs.) Sociolinguistics and Language Education. Clevedon, UK: MultilingualMatters, p. 349-369, 2010.

OLIVEIRA, C.L. Um apanhado teórico-conceitual sobre pesquisa qualitativa: tipos, técnicas e características. Revista Travessias, v.2, n.3, 2008.

SILVA, J. F. S. A construção discursiva da identidade de futuros professores de inglês: um estudo em Mato Grosso do Sul. Web RevistaDiscursividade, v. 2, n. 12, 2013.

SILVA, J. F. S. A construção discursiva da identidade de futuros professores de inglês: um estudo em Mato Grosso do Sul. Web Revista Discursividade, v. 2, n. 12, 2013.

SILVA, J. F. S. Investimentos e comunidades imaginadas na construção identitária de uma futura professora de inglês. Revista (Con)TextosLinguísticos, v. 8, n. 10, 2014.

SILVA, J. F. S. \& GIL, G. Culture, Language and Identity Construction in Foreign Language Learning and Teaching: a Theoretical Discussion. Contexturas, n. 19, 2014.

RECEBIDO EM: 13/08/2019 APROVADO EM: 15/10/2019 